ametje Formica rufa rufo-pratensis major. Beibe Balbametjenraffen gemäfren im

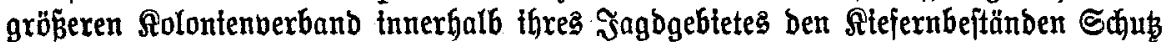

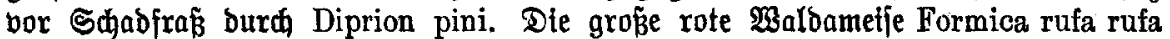
jeigt tm Freilandverjud wentg Angriffalujt gegen bie Piefernbufdhornblattwejpe,

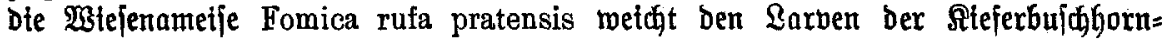

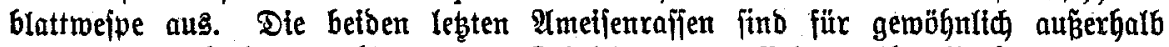
Des Şauptberbreitungşgebietes bes Schäblings zul finber, thr Berjagen geger

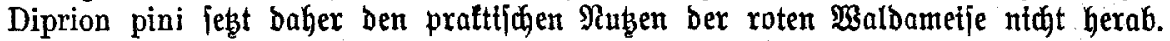
Cin anderer $\mathfrak{B a l b b e r b e r b e r , ~ B u p a l u s ~ p i n i a r i u s , ~ m i r b ~ b o n ~ f a ̈ m t l i d j e n ~} \mathfrak{B a l d a m e i j e n =}$ rafjer und zugletch bon ber \$rtejenameije angegriffen. Durd weitere in biejen

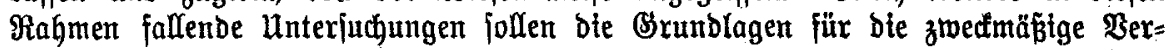

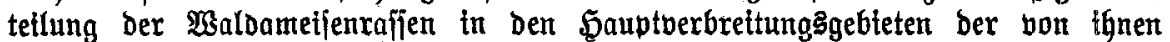
jeweils am exfolgretchiten angegriffenen Schäblinge exztelt werben, um bie lunjt= liche Maffenvermegrung Der roten Balbametje möglidłit wirfungşvoll zu geítalten.

\title{
III. Büheranjeigen
}

\author{
Nr. 19
}

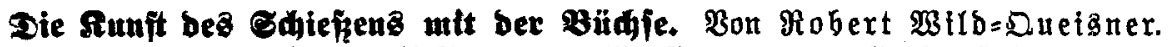
Sechjte, neubearbeitete 2 tuflage von $\mathfrak{B}$. Bemander, Baufhiefobmann ber

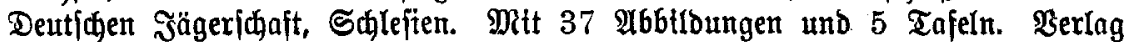

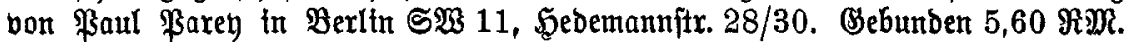

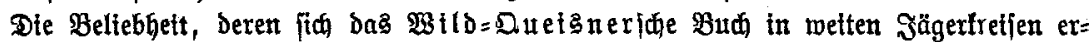

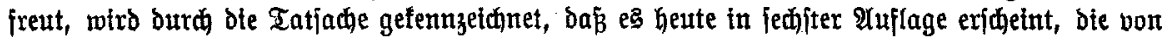

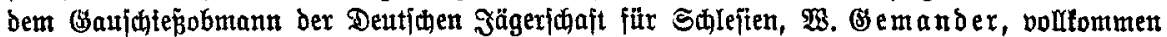

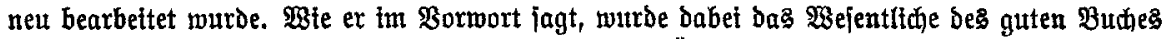

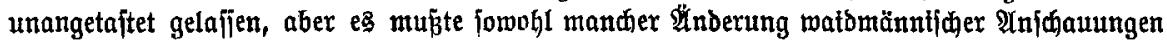

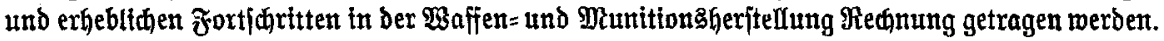

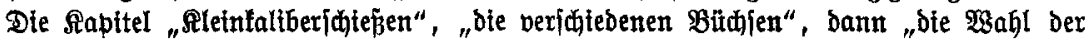

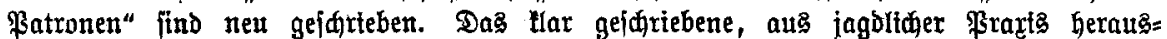

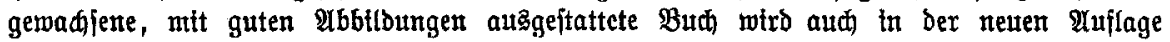

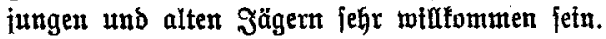

ธक.

\section{Kurze Vladhriditen}

\section{Bewertung von forftbetrieben nad der Standortsflaffe vom Bewertungs:} ftiditag

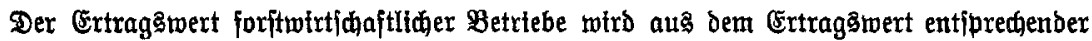
Radhalt

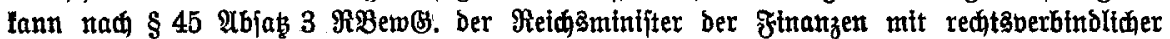

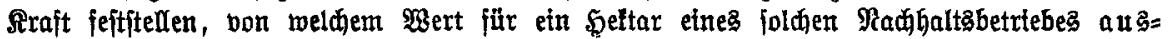

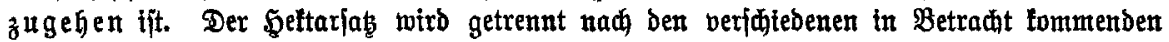

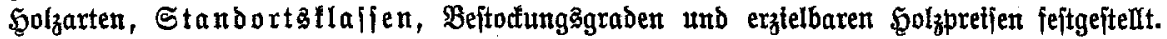

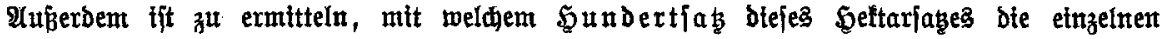

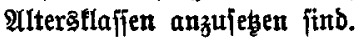

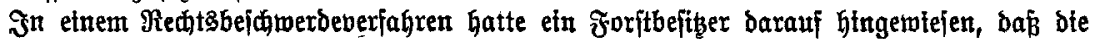

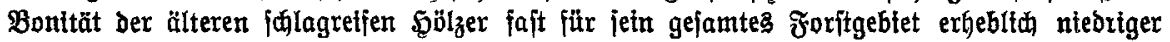

